\title{
ADEUS, FUTURO
}

\author{
ADIÓS, FUTURO
}

GOODBYE, FUTURE

\section{Janaina BEHLING}

RESUMO: Neste trabalho apresento uma resenha crítica do livro "Adeus, Futuro", de Maria do Rosário Pedreira, uma das vozes literárias mais respeitadas da cena portuguesa contemporânea. O livro, publicado em fevereiro de 2021, é resultado de uma coletânea de setenta e cinco crônicas originalmente publicadas no jornal Diário de Notícias, um dos mais influentes entre os portugueses. Entre inúmeros assuntos, algumas crônicas tratam direta ou indiretamente de questões de linguagem, letramento e ensino que permitem indagar sobre a ruptura entre a língua brasileira e a portuguesa em função de valores culturais, do humanismo e do respeito às diversidades plurilíngues.

PALAVRAS-CHAVE: Língua portuguesa. Língua brasileira. Ruptura.

RESUMEN: En este trabajo yo apresento uma recensión critica del libro Adeus,Futuro de Maria do Rosario Pedreira, una das voces más respectadas da cena literária contemporanea de Portugal. Publicado em Febrero 2021 es lo resultado de uma colécion de 75 cronicas originalmente escritas para lo periódico Diário de Notícias, uno dos más influentes de los portugeses. Dentre muchos temas, algunas cronicas directa e indirectamente permite indagar de questiones de lenguage, literacia y ensino que permiten indagar la ruptura de la lengua brasileña y la portuguesa en función de valores culturales, de lo humanismo y de lo respecto a las diversidades plurilinguísticas.

PALABRAS CLAVE: Lengua portugesa. Lengua brasileña. Ruptura.

ABSTRACT: In this assignment I present a critical review of the book Adeus, Futuro by Maria do Rosário Pedreira, one of the most respected voices of the Portuguese contemporary literary scene. Published in February 2021 it is the result from a collection of 75 chronicles originally written for the newspaper Diário de Noticias one of the most influential Portuguese newspapers. About so many subjects, some chronicles direct and indirectly focus on language questions, literacy and teaching which allow to inquire about rupture between the Brazilian language and Portuguese language in function of cultural values, humanism and respect to the plurilingual diversities.

KEYWORDS: Portuguese language. Brazilian language. Rupture.

${ }^{1}$ Universidade de Coimbra (UC), Coimbra - Portugal. Mestrado em Linguística Aplicada (UNICAMP) e exDoutoranda no Programa de Pós-Graduação em Linguística do Português (UC). ORCID: https://orcid.org/00000001-9984-1624. E-mail: janabehling@gmail.com 
Qual a diferença entre uma leitura obrigatória e um livro indispensável quando o assunto for cindir, de uma vez por todas, a língua brasileira da portuguesa?

Adeus, Futuro de Maria do Rosário Pedreira, considerada por editores proeminentes uma das vozes mais respeitadas da cena literária portuguesa, não é um livro nem exata ou exclusivamente sobre cisão linguística ou sobre a urgência de duas línguas serem definitivamente estrangeiras entre si, ainda que parecidas, ainda que cada vez menos, nesta segunda década do século vinte e um. O livro, ao contrário, é sobre muitos assuntos, tantos e tão diversos que enxergar rupturas passa a ser um exercício pontiagudo, apesar de não menos delicado e essencial como são a própria escrita da autora.

Com a abertura de espírito de quem vai explorar o desconhecido (FIGUEIREDO; BELO, 1985), tanto como leitura obrigatória quanto livro indispensável, Adeus, Futuro - lido em Portugal por olhos linguísticos brasileiros como os meus, femininos, não brancos, não ricos, não muito afeitos ao Brasil-Estado-Novo-de-Juscelino, e saídos de um doutoramento em Linguística do Português na Universidade de Coimbra (inconcluso) - creio que nesta resenha certamente modesta no mainstream tanto de acadêmicos como leigos da linguagem, podemos ao menos identificar leitores mais ou menos preparados ou carentes, de certos recursos intelectuais ${ }^{2}$, em benefício de alguma defesa de futuros científicos melhores, por um lado, e mais justos, por outro, levando em conta não apenas as limitações sofridas por colonos e colonas brasileires radicados em Portugal por "falarem brasileiro", especialmente, em escolas e universidades, mas também a oferta de produtos e serviços de mais qualidade para a vida ordinária em geral, mesmo que sejam crônicas ${ }^{3}$.

Nessa identificação de leitores, portanto, considero que uma leitura obrigatória de Adeus, Futuro - pertencente a uma coleção da editora Quetzal (irritantemente) chamada de "língua comum" - corresponde ao primeiro grupo, o dos acadêmicos da língua. E como livro indispensável, identifico como leitores aqueles que, equivocadamente chamados de leigos, acabam apenas excluídos (quando não se retiram por si mesmos) das torres de marfim dos estudos linguísticos, em especial, mais conservadoras. É evidente que, no fim, o livro pode servir como uma grande ponte entre os dois mundos na tarefa de seguirem, lusófonos e ilusófonos, como diria Marcos Bagno, seus próprios rumos.

\footnotetext{
${ }^{2} \mathrm{Na}$ acepção de Bourdieu, o intelectual como pensador independente, de dignidade específica das Letras, com a missão de pôr a sua autoridade específica a serviço das causas públicas.

${ }^{3} \mathrm{Na}$ acepção de Barthes, a escrita como o satori, que no Zen significa iluminação e sismo mais ou menos forte (e nunca solene) que faz vacilar o conhecimento, o sujeito, e opera no vazio.
} 
A capa do livro ostenta a imagem de uma mulher esguia e eurocentricamente bonita, branca, de nariz afunilado e queixo sensual; mão direita pousada num braço de poltrona ou bengala, com o indicador em riste, indicando poder; e a mão esquerda, pousada sobre as pernas encapadas por uma meia fina preta, agora com dois dedos em riste, segurando um cigarro, indica tanto poder que reproduz um corpo feminino capaz de alcançar independência com segurança e firmeza, como aparentemente ocorreu com a própria autora, em seus tantos anos de carreira como editora da Leya - aliás, desafeta de trabalhos domésticos, especialmente a culinária e satisfeitamente não mãe - e, quem sabe, também com as raríssimas catedráticas da língua brasileira de 1827, caso existissem.

Essas catedráticas, se existiram, estiveram preocupadas com o conceito de língua materna a ser ensinado nas escolas oitocentistas que, via de regra, era brasileira, mas denegou as línguas indígenas e também as africanas, como o kimbundo, conforme se pode constatar em trabalhos de História das Ideias Linguísticas brasileiras (ORLANDI, 2001). Não estou querendo insinuar que um eventual modo de conceituar "língua materna" na cabeça da senhora Pedreira, na Portugal de hoje, seja o mesmo de 1827, no Brasil. Ou estou? Na verdade, creio que seja quase o contrário, afinal, falar português no Brasil nunca foi uma escolha, mas uma saída colada com cuspe quando, junto com a noção de ruptura das línguas, não veio uma nomenclatura mais compatível ou adequada, como língua brasileira, no lugar de português do Brasil. É natural, portanto, que nos dias de hoje intelectuais não apenas portugueses e brasileiros fiquem presos a essa cola, mesmo sabendo que as línguas testemunham a história dos falantes e o curso das rupturas nunca parou.

Como resultado do cuspe, em São Paulo temos o Museu da Língua Portuguesa que, por questões óbvias, deveria se chamar Museu da Língua Brasileira. Além disso, toneladas de bobagens são proferidas e repetidas por muita gente que papagaia ser o português a sétima (ou quinta?) língua mais falada do mundo e, como li numa resenha de um livro sobre descrição do português brasileiro (FREIRE, 2021), “isso garante poder político ao português (não ao brasileiro, que não é uma língua europeia, logicamente) para pleitear ser uma das línguas oficiais da ONU e garantir que um falante de português possa 'se virar' em regiões onde há nações em que se fala português".

Acho uma pena que essa gente não saiba que, se tem algo de que a gente não precisa é da ONU para 'se virar', pelo menos, não em termos linguísticos, especialmente, quando as tensões espalhadas pelos quatro cantos do mundo que falam algum tipo de português são a verdadeira problemática histórica em que qualquer poder político não passará de (re)colonização, como já afirmaram muitos historiadores, como Silvia Scott (SCOTT, 2016). 
"Se virar" significa exatamente o quê? Não renunciar à mania molusca de ser monolíngue e, por isso, não se interessar em aprender outras línguas (para além do inglês, evidentemente) e, com isso, sobreviver superficialmente em outras culturas encorajados por nacionalismos baratos? É ter placas de sinalização nos aeroportos escritas também em...português? A União Europeia tem vinte e quatro línguas oficiais e, nem por isso, as sinalizações oficiais são repetidas vinte e quatro vezes diferentes. Para comprar coisas nos supermercados, que já trazem o espanhol como opção para "se virar", já que é esse o caso, embora haja produtos muito interessantes com embalagens em apenas francês, alemão ou até polonês, que o monolinguismo impede de conhecer? Para acionar links poliglotas que ostentam a bandeira de Portugal, mas escritos por brasileiros, por exigência da própria empresa contratante?

Crônicas à parte, creio que anos atrás tenha sido possível que, entre outros fatores, a diversidade linguística pleiteada na União Europeia deva ter inspirado Aluísio Mercadante, então Ministro da Educação, a restringir a ida de alunos brasileiros, via Ciências Sem Fronteiras, para Portugal. Nos bastidores da medida, de certa forma, talvez já estivesse o eco da ruptura entre as línguas e respectivas identidades (afinal, usar o dinheiro público para brasileiros falarem português europeu para quê? Usar mesóclise?) mas, diplomático, o Ministro deu como justificativa o fato de que os alunos brasileiros deveriam se esforçar para aprenderem outras línguas. A medida do Ministro foi considerada impopular por muitos (que pareciam ter nascido em 1827), embora, na sequência, tenha sido implantado e implementado em diferentes universidades brasileiras, também, o Programa Idiomas Sem Fronteiras que, apesar das limitações, facilitava a qualquer aluno ou aluna matriculados numa universidade o acesso, gratuito e de qualidade, de início (o Programa foi extinto e reduzido ao pagamento do TOEFL, por seus atuais opositores), à língua inglesa e depois, francesa.

Maria do Rosário Pedreira, muito mais astuta que uma leva considerável de linguistas modernosos (entre os quais os que reduzem políticas linguísticas a "se virar") e críticos capengas de políticas públicas (que reduzem a saída do monolinguismo a certificados de proficiência), sabe que a ruptura não está apenas em marcha, mas precisa ser logo assumida pelo bem dos próprios falantes de algum português, inclusive, os próprios portugueses, em respeito ao lugar que ocupam no passado das línguas e não no presente, conforme o trecho da crônica "Língua de Fora":

Contava o saudoso escritor António Alçada Baptista que uma vez, andando de táxi com um amigo numa cidade do interior do Brasil, o motorista lhes perguntou que língua vinham a falar e donde eram. Explicando-lhe que 
falavam português e vinham de Portugal, o comentário que se seguiu foi surpreendente: 'para estrangeiros, falam muito bem a nossa língua' (PEDREIRA, 2021, p. 73, grifos da autora).

Não resta dúvidas de que, para portugueses mais desavisados ou iludidos com alguma superioridade eurocêntrica, o comentário do taxista (um caipira analfabeto na cabeça dos visitantes, provavelmente) fosse surpreendente. Mas, a espontaneidade com que a noção de língua materna do suposto analfabeto foi proferida, na verdade, dá provas de uma ruptura que, quando não assumida, reforça desencontros epistemológicos que poderiam ser evitados, entre outros, em favor da elucidação portuguesa sobre as suas próprias políticas de língua minoritária que na verdade é (PINTO, 2010). Afinal, os ataques nervosos de "donos da língua" que os portugueses manifestam (com certa regularidade) em Portugal, simplesmente não têm qualquer efeito no Brasil. E, em termos de União Europeia, só restaria aos brasileiros, ironicamente, o estatuto de portugueses de segunda classe. E Mercadante, críticas à parte, acho que sabia disso.

Então, por que "raios" mais de duzentos milhões de falantes de uma língua cindida são obrigados a dizer que falam português? E é mais do que justo que os portugueses, intelectuais ou não, gozem da liberdade de não terem absolutamente nada a ver com a gente, especialmente, para garantir alguma integridade (estrangeira) aos que não fazem questão de se identificar com portugalidades. E, cônscia de sua necessidade de superar larga contradição histórica na conceituação de língua materna, a escritora parece indagar por uma liberdade condoída em nível ortográfico: “Ora, deitando-lhe o Brasil a língua de fora, irá Portugal, praticamente sozinho, fazer finca-pé numa ortografia que nem sequer é a sua?" (PEDREIRA, 2021, p. 74).

Acredito que "deitar a língua de fora", conforme resido em Portugal há três anos, estaria mais para uma expressão que indica desaforo do que necessariamente aceitação de algum tipo de emancipação linguística automatizada (apesar de colada com cuspe, como já disse) nas cabeças brasileiras tratadas como leigas. Ao mesmo tempo, a sensibilidade da autora para com a sua (nossa) emancipação é bastante superior e mais refinada que a de 1827 , por reconhecer que os portugueses estão praticamente sozinhos diante de um acordo que se deveria chamar "acordo ortográfico da língua brasileira" e que, de resto, ninguém pediu.

Todavia, resta que ela, não sozinha, mas junto com todos, todas e todes os portugueses, se disponham a entender melhor o que classifica por "erro", quando colônias brasileiras, de diversidade astronômica, povoam Portugal e lascam o português europeu (BEHLING, 2020) paulatinamente, desde a publicação de dissertações e teses 
(invariavelmente rechaçadas linguisticamente) aos famigerados cafés e esplanadas, passando por influenciadores de Youtube que invadem as casas portuguesas e as crianças (não só elas), por sinal, adoram, fazendo com que imaginemos cada vez mais duelos de linguagem e de valores (HUA, 2008) nas diferentes configurações familiares do futuro e respectivas crises intergeracionais ${ }^{4}$, já então muito problemáticas entre portugueses imigrantes que, ao procurarem escolas de sua língua materna em outros países, para os filhos e filhas, encontram aulas de...brasileiro.

Nesse caso, enquanto a ruptura não vem, "a importância de entregar um texto sem mácula" (PEDREIRA, 2021, p. 47), a despeito da relativa pobreza que a vida digital empresta aos escritores e escritoras das gerações atuais, precisa ser revisitada. E, no mercado literário, até é! Basta ver o sucesso estrondoso de Torto Arado, romance de Itamar Vieira Junior, que muito mais que um "índio a gosto" (expressão que ouvi de um comentarista de boteco da briosa), apesar ou por conta das referências literárias estadonovistas brasileiras que o embasa, de acordo com o próprio autor, foi vencedor de um concurso literário disputadíssimo da... editora Leya, e não por méritos no uso da linguagem digital, mas, entre outros, da realidade linguística brasileira. Aliás, uma vez bastante apoiado nas influências quilombolas, não deveria o referido romance ser um divisor de águas e não uma relativa nova descoberta portuguesa no mercado literário global? O que temos, então, é uma redução velada da língua brasileira, mais uma vez, a um estilo isolado (COUPLAND, 2007) do português europeu?

Assim, seria o caso de, na crônica "Língua Madrasta" (PEDREIRA, 2021, p. 61), compreendermos que "de facto" não está errado em português europeu, mas é no mínimo arcaico em brasileiro e, também, que não é "mais polido", para aqueles que ainda defendem paradigmas jurássicos de conceituação de língua materna:

De facto, desde que as novas tecnologias ditaram uma mudança de paradigma - e sobretudo por falta de leitura, mas também pela informalidade que se imprimiu à comunicação - , os jovens usam um léxico extremamente reduzido e estão mais longe de dominar a língua materna (PEDREIRA, 2021, p. 61).

Em se tratando de léxico, infelizmente, a autora provavelmente desconhece trabalhos muito interessantes sobre morfologia derivacional (RIO-TORTO et al., 2016) que, ao contrário, acusam uma versatilidade inquestionável das línguas, em particular, a portuguesa, de inventar palavras diariamente, expostas tanto na literatura quando nas urgências do

${ }^{4}$ Aliás, a ruptura entre as línguas em Portugal é tanto uma realidade que a secretária da Casa do Brasil de Lisboa, quando realizei ali uma Tertúlia sobre o português do Brasil falado em Portugal, me disse que, uma vez casada com um português, seus filhos se dirigem a ela em brasileiro e ao pai em português europeu. Não tive oportunidade de saber como isso era vivenciado junto aos avós paternos. 
cotidiano português (patobravesco, covidário etc), mas que, talvez pelas privações oferecidas pelo ideal de um texto sem mácula, é uma versatilidade apagada da escrita, dando ainda mais vazão a escritores novatos de enxergar na linguagem televisiva (que eu também considero paupérrima) o sentido da criação narrativa.

Outra coisa a se considerar é que, sendo dois sistemas linguísticos praticamente opostos - ou seja, um (o brasileiro) bastante diverso, ágil e afeito a adaptações e outro, mais hierarquizado e uniformizador (o português) - qualquer coisa considerada por "domínio da língua materna" também será praticamente oposta - o que prejudica bastante as crianças e professores vindos do Brasil ao sofrerem xenofobia nas escolas portuguesas, e não só em função do léxico, mas também das formas de tratamento, por brasileiros tratarem todo mundo por "você”, pronome que Maria do Rosário considera horrível (PEDREIRA, 2021, p. 88) sem se dar conta de que pode estar indexando ideologias da burguesia das grandes metrópoles (eurocêntricas) que, dentro de um senso muito próprio de civilidade (BOYD, 2006) olha para a diversidade como algo provinciano, no máximo exótico ou próprio de uma classe social inferior (GAL; IRVINE, 1995), talvez como a moça da capa do livro, de modo que seria interessante rever, também, este trecho da crônica "Nem tanto à terra":

\section{Porém, talvez com o receio de que o exercício da autoridade evocasse a memória do fascismo e fosse, portanto, malvisto, a disciplina e a admiração pelos mestres, tão necessárias ao sucesso pela aprendizagem, depressa se diluíram numa espécie de igualdade desproporcionada que, de resto, muitos docentes facilitaram (PEDREIRA, 2021, p. 68).}

Em termos de revisão de valores, seria o caso de nos perguntarmos se, de fato, se trata de os docentes facilitarem uma igualdade desproporcionada entre alunos e professores ou se, via de regra, a efemeridade da língua, a cada dia, tem invadido os sistemas de ensino pelo mundo afora e reduzido distâncias entre especialistas e leigos, não apenas como tecnologia pedagógica, mas como política de língua.

Uma prova de que não há nada de eventualmente desproporcional na admiração pelos mestres e mesmo no sucesso da aprendizagem, na própria Europa de modo geral, é a publicação, em 2018, de um documento chamado Common European Framework of Reference for Languages by Council of Europe (CEFR). De acordo com a apresentação do texto

Essas descrições tratam de generalizações sobre mediação - aprendizado, ensino, avaliação - de regulagem fonológica, línguas de sinais (novo, desde 
1971) e de jovens aprendizes munidos de recursos plurilinguísticos e pluriculturais na Europa (CEFR, 2018, p. 26, tradução nossa) ${ }^{5}$.

Apesar das limitações (encapsulamento de políticas de língua a esferas educacionais), o documento é extremamente interessante por apresentar avanços cruciais no modo (europeu) de pensar e agir plurilinguisticamente, algo que, grosso modo, diminui (eximir é mais difícil) a relativa autoridade de falantes nativos em relação a outros falantes, secundariza questões de origem e, consequentemente, prima pela valorização de propriedades sociolinguísticas que, no lugar de certas ou erradas, estão livres para serem respeitadas:

Figura 1 - Lista de mudanças para descritores específicos de 2001

\begin{tabular}{|l|l|}
$\mid$ FORMAL DISCUSSION (MEETINGS) \\
\hline C2 & $\begin{array}{l}\text { Can hold his/her own in formal discussion of complex issues, putting an articulate and persuasive argument, at no } \\
\text { disadvantage to native other speakers. }\end{array}$ \\
\hline INTERVIEWING AND BEING INTERVIEWED \\
\hline C2 & $\begin{array}{l}\text { Can keep up his/her side of the dialogue extremely well, structuring the talk and interacting authoritatively with complete } \\
\text { effortless fluency as interviewer or interviewee, at no disadvantage to fative other speakers. }\end{array}$ \\
\hline SOCIOLINGUISTIC APPROPRIATENESS \\
\hline C2 & $\begin{array}{l}\text { Can mediate effectively and naturally between speakers of the target language and of his/her own community of origin, } \\
\text { taking account of sociocultural and sociolinguistic differences. }\end{array}$ \\
\hline C2 & $\begin{array}{l}\text { Appreciates virtually all the sociolinguistic and sociocultural implications of language used by native proficient speakers of } \\
\text { the target language and can react accordingly. }\end{array}$ \\
\hline B2 & $\begin{array}{l}\text { Can sustain relationships with speakers of the target language native speakers without unintentionally amusing or irritating } \\
\text { them or requiring them to behave other than they would with another native-proficient speaker. }\end{array}$ \\
\hline SPOKEN FLUENCY \\
\hline B2 & $\begin{array}{l}\text { Can interact with a degree of fluency and spontaneity that makes regular interaction with speakers of the target language } \\
\text { Aativo speakers quite possible without imposing strain on either party. }\end{array}$ \\
\hline
\end{tabular}

Fonte: CEFR (2018)

Contradições à parte, é verdade que o mercado literário, muito mais esperto que o ensino (para variar) se beneficia de Torto Arado como obra que cumpre os requisitos da CEFR como política de língua, (diminui a autoridade de falantes nativos, secundariza questões de origem, prima pela valorização de propriedades sociolinguísticas), embora isso possa se traduzir no famoso "fazer bonito com o chapéu alheio"6.

Todavia, sobre rupturas, resta também a gente pensar melhor a vida ordinária e educativa de brasileiros e portugueses na Europa, especialmente em território português, quando todos, até mesmo Maria do Rosário Pedreira, na crônica "Merecer", fala de algo sobre

5 "These descriptions were about generalizations of mediation - learning, teaching, assessment - phonological control, sign languages (new aspect since 1971) and young learners involved in plurilingual/pluricultural arms in Europe" (CEFR, 2018, p. 26).

${ }^{6} \mathrm{Na}$ acepção do filósofo José Gil, algo como o esforço da impossibilidade de dar forma a um fundo visceral sem forma. 
seu passado educacional, com o fim do salazarismo, que devemos sonhar para o futuro: "Depois de um ensino categórico e papagueante, parecia que todas as portas se tinham finalmente aberto para podermos arejar as nossas cabeças" (PEDREIRA, 2021, p. 72).

Pensando ainda no conceito de língua materna que contorna a ideia de ruptura das línguas, acrescento que, para sair não apenas de um ensino, mas de uma vida papagueante, não é apenas lançando mão de alguma linguística histórica, deambulações lexicais, dramas pedagógicos e gráficos corrigidinhos em vermelho, que essa(s) ruptura(s) vai(vão) merecidamente arejar nossas cabeças. Porque, afinal, a Linguística, tanto a Geral quanto a Aplicada são áreas de estudo vastíssimas e tão complexas que podemos sonhar (ou exigir) que não precisem demorar mais duzentos anos para ajudar as pessoas a terem uma qualidade de vida linguística melhor, em função de valores culturais, do humanismo e do respeito às diversidades plurilíngues.

Falando em qualidade de vida linguística, passo agora a contemplar Adeus, Futuro como um livro indispensável para todos que ainda são capazes de compreender o português europeu de alguma forma. "De alguma forma" porque, como já afirmei anteriormente, em se tratando das colônias brasileiras instaladas em Portugal e sua enorme diversidade linguística, reconhecer que falamos brasileiro é ainda, exceto em casos interessados, algo pejorativo e genérico, apesar dos esforços da União Europeia.

Afinal, ainda estamos na fase de perguntar: qual brasileiro? Do Piauí? De Santa Catarina? Do Sergipe? Falado onde? Na região do D’Ouro? No Alentejo? Em Lisboa? Ainda não sei, muito sinceramente, como esse tipo de dúvida tira ou põe comida na mesa imigrante, mas conheço quem ache de extrema importância. Nesse ponto, Maria do Rosário Pedreira dá um verdadeiro show ao salientar, com toda sua respeitosa autoridade literária que "[...] o desconhecimento da língua afecta de forma decisiva a compreensão de qualquer texto de qualquer matéria, incluindo as que, à primeira vista, dispensam a palavra" (PEDREIRA, 2021, p. 62).

Se referindo ao desconhecimento da língua, no caso, o português europeu em relação ao brasileiro e vice-versa, não é possível discordar que esse desconhecimento afeta a compreensão não apenas dos textos, que não são apenas escritos - conforme a complexidade que caracteriza gêneros textuais e discursivos também seja muito vasta - mas também "não escritos", como o próprio corpo estrangeiro em movimento, por exemplo, e os seus silêncios ou silenciamentos que dispensam as palavras.

Sobre esses assuntos - imigração, corpo, silêncio, língua - peço licença às/aos eventuais leitores para puxar a sardinha da ruptura para o lado de uma certa ludicidade, 
responsável e responsiva, que venho construindo entre os fundos da cozinha onde trabalho, depois que abandonei o doutorado, e horas de solidão num apartamento abandonado, em Figueira da Foz, e contar que tenho me debruçado na caracterização de um gênero performativo (literário?) chamado corpo-crônica, no qual construo ou mesmo descrevo, a partir de leituras subjetivas de dados etnográficos (BEHLING; BLANCO; SARAIVA, 2019) uma certa morfologia do gesto em Portugal que se dá a partir de situações imigrantes das mais inusitadas, daí o nome corpo-crônicas (BEHLING, 2021). Tenho uma colega de trabalho, auxiliar de cozinha portuguesa praticamente desde a infância e surda de nascença, que tem me ajudado bastante porque, apesar da fala (muito) difícil (para mim) de entender, produzida com o apoio de aparelhos auditivos, ela possui, aos vinte e quatro anos de idade, uma sensibilidade e um vocabulário gestual impressionantes, maravilhosos, especialmente diante da relativa contenção básica do corpo português em geral.

Para aprofundar o estudo que dá origem às corpo-crônicas, revestidas de uma prosa poética, digamos, inconfundível, porque explora bastante a língua brasileira de diferentes regiões do Brasil (e que para minha colega "é tudo brasileiro", embora, quando eu peça para se lembrar de palavras brasileiras apareçam, com entonação sofisticada, "oxente" e “eitapoha”, típicos acho que de alguma gramática já própria da hotelaria portuguesa, não sei) e seus impactos no cotidiano português, tenho também me debruçado, muito recentemente, por sugestão da Raquel Freitag, no estudo de programas de reconhecimento facial.

No entanto, entendi, por intermédio de Adeus, Futuro, que em Portugal é melhor não me entusiasmar com estudos de programações neurais da gramática facial, porque, por um lado, conforme a crônica "O fim da empatia",

Se, como refere Manguel [Alberto], a literatura parece não ter uma utilidade evidente, a ciência agora veio mostrar que a ficção tem, afinal, um valor social inestimável, porque nos torna mais disponíveis para o outro, o que é especialmente relevante nos nossos dias, em que grande parte dos problemas (catástrofes naturais, crises migratórias, incumprimento dos direitos hum2021s...) exige soluções coletivas (PEDREIRA, 2021, p. 82).

Mas, por outro, a criação de gêneros performativos, associada a sistemas de análise computadorizada do corpo, provavelmente contribuem muito pouco, ou até nada, para tornar interessante (ou palatável?) a morfologia de gestos não europeus, diferente do que aconteceu com estudos de detalhes microssemióticos indexicalizados em corpos chineses em Londres (HUANG, 2010), por exemplo, porque segundo a própria Maria do Rosário, ao descrever o depoimento de um amigo, de fato, “[...] os jovens sabem na ponta da língua o significado de todos os emojis; mas, curiosamente, têm dificuldade em identificar, numa série de fotografias, 
se o sujeito está zangado, alegre, assustado, aborrecido ou boquiaberto de espanto" (PEDREIRA, 2021, p. 82).

Não creio que seja essa dificuldade de identificação de emoções expressas pela face exclusiva dos jovens, especialmente os portugueses, e especialmente quando se trata de encontrar soluções coletivas para problemas de ordem planetária, como a xenofobia linguística e, também, especialmente depois dos duros (e ainda não sabemos o quão traumáticos) confinamentos que enfrentamos por conta de uma pandemia mundial.

E, na verdade, pela minha experiência de estudante em Coimbra, nos tempos em que frequentei as disciplinas do doutorado, também não posso negar que me lembrei muito do tempo de Unesp de Assis, como aluna de graduação e professora aprendiz do $\mathrm{PEJA}^{7}$ e de Unicamp, como mestranda na área de Língua Materna, e não me identifiquei com aquela atmosfera estudantil europeia, nem com meus colegas ou com a falta de grupos de estudo e pesquisa e a falta de ofertas permanentes de trabalhos, digamos, de mais prestígio ou não subalternizados, porque dignas, essas experiências brasileiras, de uma formação especializada mais comprometida, justamente, porque gratuita.

Talvez essa não identificação tenha se dado porque as universidades públicas brasileiras sejam realmente públicas, ou seja, são pagas com o dinheiro dos impostos recolhidos da população e, por mais que isso venha mudando de forma absolutamente irresponsável, foram feitas para a população, em toda a sua diversidade, então é maior a responsabilidade por responder por algo que, pelo menos até onde percebo, a Europa em geral desconhece, salvas eventuais exceções: a extensão universitária.

Sem uma prática de extensão universitária a revisão da noção de habitus como potência transformadora de ações locais (ERICKSON, 2001) torna a vida estudantil ainda mais sem sentido para a resolução de problemas coletivos, de forma que faz muito sentido, na crônica "Não sabe, não responde" a autora salientar que "[...] uma parte significativa da juventude portuguesa prefere manter-se na ignorância a inteirar-se e intervir responsavelmente nos destinos do País" (PEDREIRA, 2021, p. 86).

\footnotetext{
7 Programa de Alfabetização de Jovens e Adultos chancelado pela Pró-Reitoria de Extensão que na sua constituição original reunia alunos bolsistas de todas as unidades da Unesp, dos cursos de licenciatura, para comporem um laboratório de práticas e metodologias de alfabetização e letramento de adultos onde quer que a unidade universitária estivesse instalada. Duas vezes por 2021, na cidade de Bauru, os então trinta e cinco bolsistas eram reunidos, junto a respectivos e respectivas coordenadores locais, e trocavam experiências, referenciais bibliográficos e materiais didáticos muitas vezes inusitados, devido ao local de funcionamento das classes de EJA que era desde salas de presídio a hospitais psiquiátricos; cooperativas de refinamento de açúcar, acampamentos do MST e chão de fábrica automobilística. Entre o início do 20212000 e final de 2001 o projeto registrou a passagem de centenas de pessoas por essas salas de aula. E nem sequer éramos formados, ainda.
} 
Mais uma vez, não creio que seja próprio apenas da juventude portuguesa se manter na ignorância, mas próprio da juventude das pseudo-grandes elites, que, no caso europeu - a contar pelo programa Erasmus Mundus, ao financiar o turismo universitário, desvaloriza relações duradouras, despreza epistemologias várias e associa o tempo de estudo a projetos fictícios, sem importância efetiva, destinados à conclusão de um semestre qualquer - mantém reduzida a vida na cidade a bares e festas poliglotas ${ }^{8}$, mas chatíssimas e, pior, clandestinas em tempos pandêmicos, como muitas que ocorreram na Holanda, na Itália, na Espanha e também no Brasil, claro, a despeito da saúde coletiva e do respeito às fragilidades alheias, regadas a perfume caro e cerveja barata (e quente!) que, de resto, limitam a coleta de dados para exercícios de leitura neuro-facial imigrante, porque tudo o que temos são olhos literalmente parados.

Creio que, nesse ponto, o da apatia generalizada, tanto eu quanto Maria do Rosário Pedreira e "a torcida do Corínthians" somos todos favoráveis à ruptura da língua brasileira da portuguesa, porque ainda que os rituais de passagem universitária, por exemplo, sejam os mesmos em toda parte, assim como as xenofobias, da confecção de trabalhos estudantis sem sentido e relativamente mal escritos aos encontros tangencialmente superficiais ocorridos em outras esferas sociais, ainda podemos querer defender um futuro melhor longe de eurocentrismos enviesados, sem distorções dos papéis de jovens e velhos nessa empreitada e sendo preferível, inclusive, que programas como o Ciência sem Fronteiras seja temporariamente suspenso mesmo, porque é necessário muito mais preparo e responsabilidade para ser e receber intercambistas provindos de tradições linguísticas, no caso, pautadas no elitismo provinciano das línguas.

Para terminar, falando em conservadorismos, Adeus, Futuro, que trata ainda de tantos outros assuntos cotidianos e suas respectivas inversões de valores, é uma oportunidade maravilhosa de ponderarmos, com o apoio de coerência e coesão magistrais, sobre o lugar e o valor de nossos respectivos passados linguísticos, em toda a sua diversidade para, com mais lucidez, tratarmos dos sintomas da falta de letramento imigrante com mais rigor, como prática de emancipação de monolinguismos e de reconsideração de estatutos sociais situados, a partir de uma noção mais ampliada de língua materna e de diversidade linguística que, no caso do brasileiro, não é um arremedo do português europeu, como muitos ainda consideram, direta ou indiretamente.

\footnotetext{
${ }^{8}$ Algumas das quais, em homenagem à minha "presença", tocavam o chamado 3B (Bum Bum Brasil) ou o pimba, com suas letras escandalosamente misóginas. Quando não, era o mais enfadonho da mpb, aquele, estadonovista, em que velhos desocupados babam por ninfetas cariocas. Chego ao ponto de preferir as músicas gospel, todas em brasileiro, que minha colega surda escuta no trabalho.
} 
É outra língua. Adeus, futuro.

\section{REFERÊNCIAS}

BARTHES, R. O prazer do texto precedido de variações sobre a escrita. Lisboa: Edições 70, 2009.

BEHLING, J.; BLANCO, M.; SARAIVA, C. Linha de Fuga 2018: documentação e práticas de arquivo subjetivas num laboratório de artes performativas. Imprensa da Universidade de Coimbra, 2019.

BEHLING, J. O “brasileiro” como língua de afirmação em Portugal. Rev. Prolíngua, v. 15, n. 1, p. 67-81, 2020. DOI: 10.22478/ufpb.1983-9979.2020v15n1.52198.

BEHLING, J. Corpo-Crônicas de uma brasileira numa Pandemic Portugal. Porto Alegre: Simplíssimo, 2021.

BOURDIEU, P. As regras da arte. Génese e estrutura do campo literário. Colecção Biblioteca do Século. Lisboa: Presença, 1996.

BOYD, R. The value of civility? Urban Studies, v. 43, n. 5-6, p. 863-878, 2006.

COUPLAND, N. Style. Cambridge: Cambridge University Press, 2007.

ECO, U. Conceito de texto. Trad. De Carla de Queiroz. São Paulo: T.A. Queiroz, Ed. da Universidade de São Paulo, 1984.

ERICKSON, F. Co-membership and wiggle room: some implications of the study of talk for the development of social theory. In: COUPLAND, N.; SARANGI, S.; CANDLIN, C. (Eds.). Sociolinguistics and social theory. 2001. p. 152-18.

FIGUEIREDO, M. J. V.; BELO, M. T. Comentar um texto literário. Lisboa: Presença, 1985.

FREIRE, J. B. O manual da descrição do português brasileiro. Rev. EntreLínguas, Araraquara, v. 7, n. 00, e021007, 2021. DOI: 10.29051/el.v7i00.14521

GAL, S.; IRVINE, J. The boundaries of languages and disciplines: How ideologies construct difference. Social Research, v. 62, n. 4, p. 967-1001, 1995.

GIL, J. Portugal hoje: o medo de existir. 14. reimpr. Lisboa: Relógio d'Água, 2017.

HUA, Z. Duelling languages, duelling values: codeswitching in bilingual inter-generational conflict talk in diasporic families. Journal of Pragmatics, v. 40, p. 1799-181, 2008.

HUANG, A. London Chinatown: A sociolinguistic ethnography of visuality. PhD diss. University of Jyväskyla, 2010. 
ORLANDI, E (org.). História das Ideias Linguísticas: construção do saber metalinguístico e constituição da Língua Nacional. 1. ed. Campinas: Pontes, Cáceres: UNEMAT Editora, 2001.

PEDREIRA, M.R. Adeus, Futuro. Lisboa: Quetzal, 2021.

PINTO, P.F. O essencial sobre política de língua. Portugal: Imprensa Nacional-Casa da Moeda, 2010.

RIO-TORTO, G. M. et al. Gramática Derivacional do Português. Imprensa da Universidade de Coimbra, 2016.

SCOTT, S. Os portugueses. São Paulo: Contexto, 2016.

\section{Como referenciar este artigo}

BEHLING, J. Adeus, futuro. Rev. EntreLínguas, Araraquara, v. 7, n. 00, e021034, 2021. eISSN: 2447-3529. DOI: https://doi.org/10.29051/el.v7i1.15487

Submetido em: 10/08/2021

Aprovado em: 15/09/2021

Publicado em: 08/10/2021 